\title{
27. TETRAPYRROLE PIGMENTS FROM IPOD LEG 47B, HOLE 398D
}

\author{
Susan E. Palmer, Department of Geology, and Earl W. Baker, Department of Chemistry, Florida Atlantic \\ University, Boca Raton, Florida
}

\section{INTRODUCTION}

We analyzed the tetrapyrrole content of 13 samples from Site 398 that range in age from Miocene to Early Cretaceous and at a sub-bottom depth from 400 to 1660 meters. Site 398 is located $90 \mathrm{~km}$ off the coast of northern Portugal, south of the Vigo Seamount.

Most surprising was the presence of chlorins in both the shallow $(400 \mathrm{~m})$ and deeper $(1070-1660 \mathrm{~m}) \mathrm{sam}$ ples; the presence of chlorins is usually indicative of thermally immature sediments. Previously, chlorins were not found below 1000 meters, but more typically gave way to free-base and metalloporphyrins at that and greater depths (Baker et al., 1978a, c). An anomalously low temperature gradient of $1^{\circ} \mathrm{C} / 100 \mathrm{~m}$ reported by the Leg 47B shipboard party could explain the presence of these diagenetically immature pigments below 1000 meters. The depositional environment and nature of the organic matter deposited, however, may also play a significant role in the observed diagenetic products.

A second surprising feature of these cores is the absence of free-base porphyrins. Free-base porphyrins indicate an intermediate stage of chlorophyll diagenesis (referred to as the chlorin-porphyrin transition). Perhaps the free-base porphyrins were formed and later erased from the record; thus, chlorins and nickel porphyrins occur together.

Total pigment content ranged from $1.0 \mu \mathrm{g} / \mathrm{g}$ to a nondetectable amount (the average value for the 13 samples studied was $0.11 \mu \mathrm{g} / \mathrm{g}$ ); however, only two samples (from Cores 75 and 122) contained more than $0.1 \mu \mathrm{g} / \mathrm{g}$. For comparison, average pigment concentrations for samples from off the west coast of Africa ranged from $0.06 \mu \mathrm{g} / \mathrm{g}$ ( Leg 47A) to $5.5 \mu \mathrm{g} / \mathrm{g}$ ( $\mathrm{Leg}$ $41)$ and $8.0 \mu \mathrm{g} / \mathrm{g}(\mathrm{Leg} \mathrm{40)}$.

\section{EXPERIMENTAL}

Samples collected for organic geochemical studies were stored at 2 to $4^{\circ} \mathrm{C}$ for 3 weeks while in transit from Glomar Challenger to the DSDP depository at Scripps Institution of Oceanography. The cores were stored frozen thereafter until time of analysis. One hundred grams (wet weight) of sediment were extracted with acetone:methanol $(9: 1)$ in a ball mill until the extract was devoid of pigment. Type and quantity of pigment was determined by spectrophotometry using a Perkin-Elmer 575 scanning spectrophotometer. Crude extracts from samples taken from Cores 75 and 122 were chromatographed over Sephadex LH-20 with THF $(20 \times 2.5 \mathrm{~cm}$ bed dimensions $)$. Separations of chlorins from nickel porphyrins were made by partition between $\mathrm{HCl}$ and ethyl ether. Nickel porphyrins were then chromatographed over Alumina Grade III with cyclohexane:benzene (1:1). Ratios of the $\alpha(552 \mathrm{~nm})$ to $\beta(516 \mathrm{~nm})$ visible wavelength band intensities were computed for each nickel porphyrin fraction.

Solid probe mass spectrometric analyses were made on the nickel porphyrin fractions from Cores 75 and 122 using a Dupont 491-BR mass spectrometer. Source and probe temperatures were $280^{\circ}$ to $320^{\circ} \mathrm{C}$. Although analyses were attempted on porphyrin isolates from Cores $81,84,97$, and 118 , interpretable spectra were not obtained, probably because of insufficient sample material.

\section{RESULTS AND DISCUSSION}

Individual pigment yields, organic carbon content, and geologic age for Hole 398D samples are given in Table 1. Cenozoic samples (Cores 5 and 37 ) are primarily carbonate and contain only trace amounts of chlorin. This trend was noted in earlier studies (Baker et al., 1978a, b; Baker and Palmer, this volume, Part 1, Leg 47A Report). In contrast, nickel porphyrins are present in the Lower Cretaceous samples. These are usually at higher concentrations than the chlorins, which are present in only 55 per cent of these samples.

Only two of the samples (from Cores 75 and 122) shown in Table 1 contain $0.1 \mu \mathrm{g} / \mathrm{g}$ or more pigment. For this reason, electronic spectra of chlorins were obtained for only these samples. The organic extract of the Core 75 sample was separated by Sephadex LH-20 chromatography into two chlorin fractions: an earlyrunning fraction containing about 20 per cent of the total chlorins and a later-running fraction which contained the bulk of the chlorins. The electronic spectral data for these two fractions are slightly different. The early-running fraction has a red band at $660 \mathrm{~nm}$, while the red band for the late-running fraction is at $658 \mathrm{~nm}$. Further purification of the chlorin fractions through partition between $\mathrm{HC} 1$ and ethyl either required 10 to 30 per cent $\mathrm{HCl}$ (by wt.) to extract the early-running fraction from the ether layer. However, most of the pigment in the later-running fraction was extractable with only 10 to 20 per cent $\mathrm{HCl}$. In contrast, isolation of the geochlorins from the Core 122 sample resulted in only one column fraction which was readily extracted from ether with 10 to 20 per cent $\mathrm{HCl}$. In this case, the red band was at $647 \mathrm{~nm}$. Geochlorins with absorbances in this region are reported for Cretaceous samples from Leg 43 and often occur with free-base porphyrins (Palmer et al., 1979). 
TABLE 1

Tetrapyrrole Pigment Data From Leg 47B, Site 398

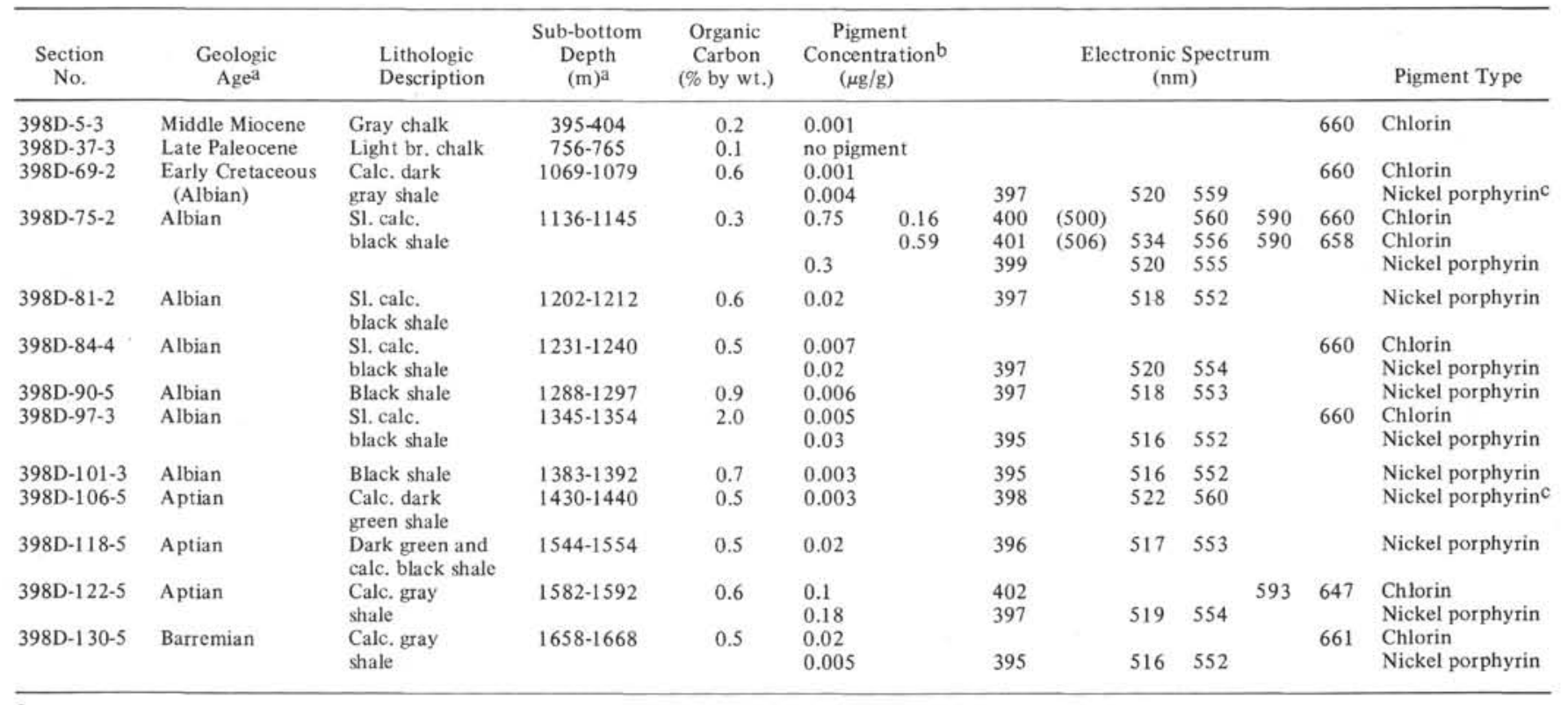

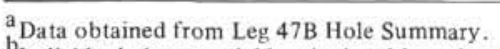

Individual pigment yields calculated by using the following molar extinction coefficients: pheophy tin "a" $=63,700 \mathrm{at} 660 \mathrm{~nm}$, nickel porphyrin $=34,820$ at $550 \mathrm{~nm}$.

The electronic spectra are similar to copper porphyrin.

Earlier studies containing more comprehensive observation of the changes in the geochlorin fraction with depth (Baker et al., 1978c, d) indicated that chlorins extracted from the more deeply buried cores have lower $\mathrm{HCl}$ numbers (i.e., 10) and form the late-running fraction on Sephadex columns. In addition, the UV-visible red bands shifted noticeably with increasing geologic age and depth of burial, from 663 to 660 to $658 \mathrm{~nm}$ and even as low as $640 \mathrm{~nm}$. Metallochlorins have red bands at $640 \mathrm{~nm}$, however, the pigments discussed here are extractable into $\mathrm{HCl}$, a characteristic of free-base chlorins and porphyrins. The data given here for samples from Cores 75 and 122 , coupled with earlier data, suggest that de-esterification and reduction of the geochlorin molecule increases with sub-bottom depth.

It is remarkable, however, that these compounds at these depths have not undergone aromatization resulting in conversion to the free-base porphyrin. Free-base porphyrins are the expected intermediate diagenetic products and have been observed in sediment samples from the Black Sea (DSDP Leg 42B) as well as in Cenozoic and Cretaceous samples from the Atlantic (Legs 38 through 44) where they occur either alone or with chlorins and/or nickel porphyrins. In contrast, freebase porphyrins are absent from these mixtures, which suggest a conversion to dihydroxyporphyrins whose electronic spectra would not be unlike those of chlorins derived more directly from chlorophyll (Baker and Smith, 1975). Whether dihydroyporphyrins occur in sediments or are artifacts formed by sample handling (for example, in this case by unfrozen storage, see experimental section) is not known. It has been long established that chelation with nickel or vanadyl has a stabilizing effect on the porphyrin nucleus. Porphyrins chelated with nickel are more likely to survive than those remaining in the free-base state. If the Cretaceous sediments in Hole 398D were deposited under oxidizing conditions, either explanation (i.e., conversion to dihydroxyporphyrins, or selective preservation of metal chelates) could explain the observations.

The ratio of the visible light absorbance bands, $\alpha$ $(552 \mathrm{~nm})$ and $\beta(518 \mathrm{~nm})$, of the nickel porphyrins are reported in Table 2 . A gradual shift in the $\alpha / \beta$ ratio occurs with increasing depth; porphyrins from shallower samples have ratios of 1.8 to 2.0 while deeper samples have ratios of 2.2 to 2.5 . A similar trend is found in nickel porphyrin isolated from Miocene core samples of Leg 47A at approximately the same depths of burial. However, the change for the Leg 47A samples is faster and the trend more noticeable. Samples from Cores 75 through 97 are Albian in age and (with the exception of the Core 90 sample) have similar lithologies and nickel porphyrin $\alpha / \beta$ ratios of 1.8 to 2.0 . It is the deeper samples, Cores 101 through 130 , that display a

TABLE 2

\begin{tabular}{ll}
$\begin{array}{c}\alpha / \beta \\
\text { Patios of Nickel } \\
\text { Porphyrins From } \\
\text { Leg 47B Core } \\
\text { Samples }\end{array}$ \\
\hline Section No. & $\alpha / \beta$ \\
\hline 398D-75-2 & 2.0 \\
398D-81-2 & 1.8 \\
398D-84-4 & 1.8 \\
398D-90-5 & 2.0 \\
398D-97-3 & 1.8 \\
398D-101-3 & 2.1 \\
398D-118-5 & 2.2 \\
398D-1 22-5 & 2.2 \\
398D-130-5 & 2.5
\end{tabular}


trend in peak ratios (Table 2). A gradual increase in the $\alpha / \beta$ peak ratio is indicative of enrichment of the etio series with depth due to thermal stress. The change results from the rupture of the isocyclic ring in nickel DPEP yielding a nickel porphyrin of the etio series. This is based on the fact that synthetic nickel DPEP has an $\alpha / \beta$ ratio of 2.0 while the value for nickel etioporphyrin is 3.0. This trend is followed by geoporphyrins. Since these are complex mixtures, the peak ratios do not coincide exactly with those of synthetic mixtures, but it is reasonable to assume that a parallel trend occurs. For example, in geologic samples, an $\alpha / \beta$ ratio of 2.1 to 2.2 is indicative of an approximate $3: 1 \mathrm{mix}-$ ture of DPEP to etioporphyrins, while a slight increase in the ratio to 2.3 would indicate a $2: 1$ mixture of DPEP to etio (Baker and Palmer; this volume, Part 1; Baker et al., 1978b). Likewise, in geologic samples, a/b values of 3.0 or greater can be indicative of a 1:1 mixture.

Mass spectrometric data of the nickel porphyrin fractions from Cores 75 to 122 are given in Table 3 . Eight members of both a DPEP/ and an etio series are present in Core 75 . The major peak corresponds to a C-26 nickel porphyrin of the etio series; however, an equally intense peak for the C-28 member is present. Also present are two members of the $455+$ $14 n$ and six members of the $457+14 n$ series. Metalloporphyrins having these molecular weights are observed accompanying free-base porphyrins and chlorins in other Cretaceous samples (Legs 43, 44, and $47 \mathrm{~A})$. In these earlier reports, the electronic and mass spectrometric data for the odd molecular weight series of metalloporphyrins have been included with the nickel porphyrin fractions because they co-chromatograph with the nickel porphyrin fraction on Alumina and their electronic spectra are similar to that of a nickel porphyrin. As indicated in Table 1, metalloporphyrins having visible bands at 520 to $522 \mathrm{~nm}$ and 559 to $560 \mathrm{~nm}$ may not be nickel porphyrins (Cores 69 and 106). Bands at these wavelengths more closely resemble copper porphyrin. The mass spectrometric series $(455+14 n$ and $457+14 n)$ suggest chelation of porphyrins of the DPEP and etio series with copper. For example, DPEP has a molecular weight of 476 , chelation with copper increases the $\mathrm{m} / \mathrm{e}$ to 537 ; likewise copper etioporphyrin has a molecular weight of 539 . Further analyses are required to determine the structure of these pigments. Once the structures are established, then a hypothesis concerning their significance in the diagenetic pathway(s) of chlorophyll can be developed.

A predominance of the etio series in the Core 75 sample results in a low DPEP/etio ratio of 0.6. If the mixture was composed only of nickel porphyrins, then the expected $\alpha / \beta$ ratio would be approximately 3.0. However, as reported in Table 2 , the observed $\alpha / \beta$ ratio is 2.0 . Since the odd molecular weight series makes up 28 per cent of the mixture, a lower $\alpha / \beta$ ratio results. Previously, a sample composed of 81 per cent of these metalloporphyrins had an $\alpha / \beta$ ratio of 1.5 (Baker and Palmer, this volume, Part 1).

The DPEP series made the major contribution to the nickel porphyrin fraction isolated from the Core
122 sample. The DPEP/etio ratio is 2.0 when determined mass spectrometrically. In this case, five members of both the DPEP and etio series are present and the most intense peak corresponds to a $\mathrm{C}-30$ porphyrin in the DPEP series. Three members of the odd molecular weight series are present to the extent of 22 per cent. As in the case of the Core 75 sample, the DPEP/ etio ratio is not predictable from the ratio of the visible bands given in Table 2. Again, the presence of the odd molecular weight component causes a slight lowering in the visible band ratios from an expected value of 2.3 for a 2:1 mixture of nickel DPEP plus etioporphyrins to an $\alpha / \beta$ ratio of 2.2 which would indicate a greater contribution by the DPEP component.

\section{CONCLUSIONS}

Several interesting observations result from a study of the data presented in Tables 1 to 3. First, the distribution of pigments with depth is contrary to that seen in previous studies where chlorins give way to freebase and metalloporphyrins with increasing depth and age. For example, earlier studies of Cretaceous samples collected from passive margin sites (Legs 40, 41, 43, 44 , and $47 \mathrm{~A}$ ) show that chlorins were restricted to samples from 450 to 960 meters sub-bottom depth. Free-base porphyrins were present at 450 to 1040 meters and nickel porphyrins were found in Lower Cretaceous samples at 550 to 1040 meters. Vanadyl porphyrins were only found in the deeper samples at 1010 to 1190 meters (Leg 40). In view of these background data, free-base and metalloporphyrins are expectable in the Lower Cretaceous samples from Hole 398D, which are at 1070 to 1660 meters depth of burial. However, in the Core 122 sample, at 1582 meters, onethird of the pigment present is chlorin. No vanadyl porphyrin is present even in the deepest samples. Thus, the distribution of pigments shown in Table 1 suggests that the organic matter present in these core samples is thermally immature relative to other samples collected from over 1000 meters sub-bottom depth. This is explained by the low thermal gradient, $1^{\circ} \mathrm{C} / 100 \mathrm{~m}$, reported by the shipboard party (Leg 47 Shipboard Party, 1976).

The second observation is that the nickel porphyrin $\alpha / \beta$ ratios do not increase as rapidly as is expected for sediments buried at these depths. The increase of the odd molecular weight series can suppress the effect of increasing amounts of etioporphyrins as was pointed out above, but this effect decreases with decreasing amounts of this odd molecular weight material. The effect of these compounds on the visible and mass spectrometric data is now being analyzed. Mass spectrometric data were obtained only on samples from Cores 75 and 122, which are unique since they contain 10 to 100 times more pigment than the 11 other samples studied (Table 1). The data from the Core 75 sample show a dealkylated series of porphyrins with major peaks at C-28 to C-26. The fact that eight members are present in both the DPEP and etio series and that $\mathrm{C}-28$ and $\mathrm{C}-26$ are in almost equal abundance suggests two populations. Usually five or six members 
TABLE 3

Mass Spectrometric Data for Metalloporphyrin Fractions Isolated From Leg 47B, Site 398 Cores $^{\mathrm{a}}$

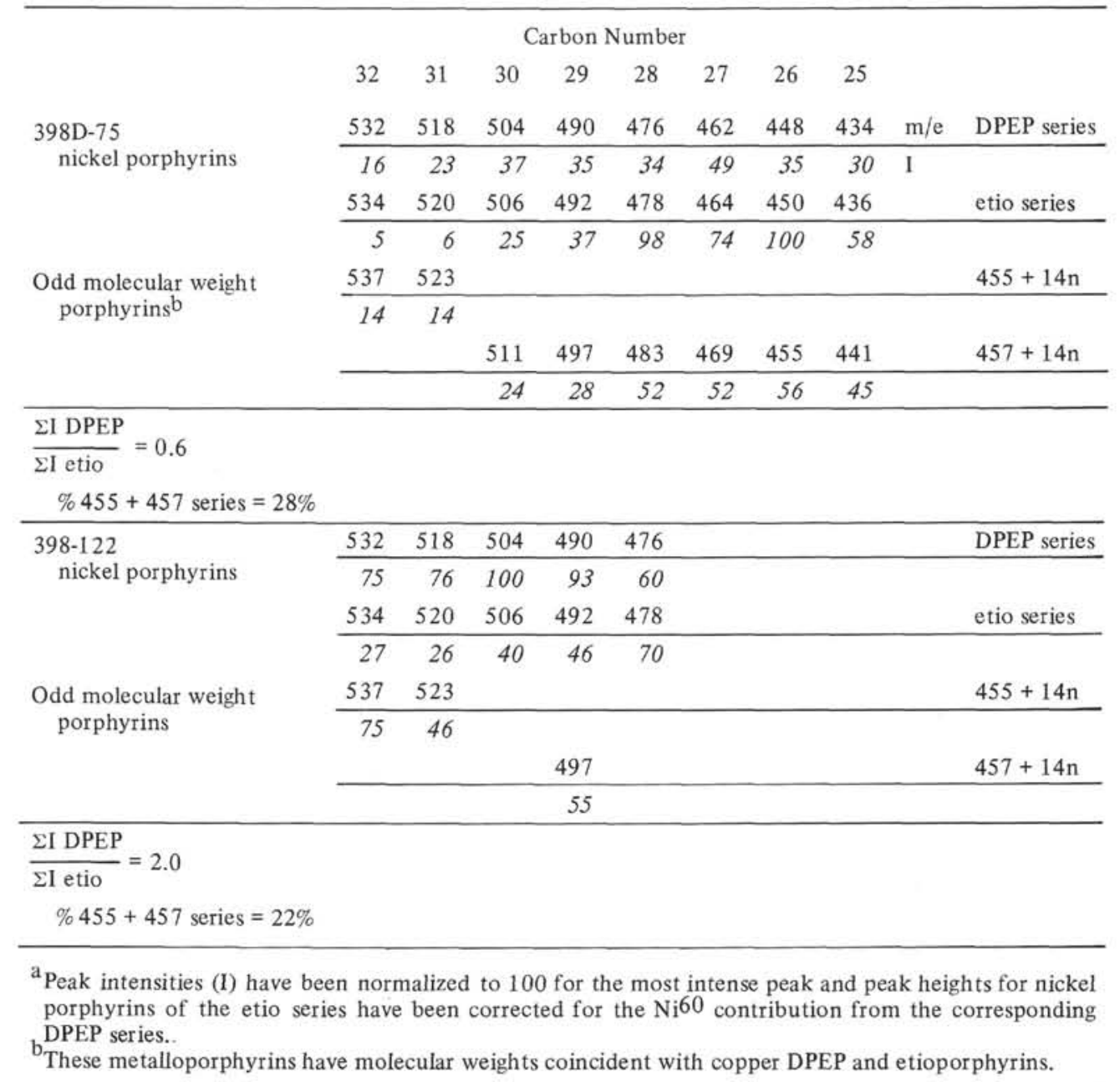

are present in each series with only one peak, typically a C-32 to C-30 porphyrin, being the most intense. Lower molecular weight members (C-29 to C-25) of nickel porphyrins of the DPEP and etio series occur with the odd molecular weight series in samples from the Black Sea and in other Cretaceous samples from the Atlantic, the most demonstrative example being from Section 47A-397-68-2 (Baker and Palmer, this volume, Part 1). The 28 per cent contribution of the odd molecular weight series plus accompanying nickel etioporphyrins lowers the DPEP/etio ratio to less than 1:1 in the Core 75 sample, where a $3: 1$ or $2: 1$ ratio is expected for samples of the same age and depth (roughly $1100 \mathrm{~m})$.

In contrast, the Core 122 sample contained a nickel porphyrin fraction which has only five members of both series and a smaller component of the odd molecular weight series. This is reflected in both the visible and mass spectrometric determinations of relative amounts of nickel DPEP and etio porphyrins (Tables 2 and 3 ). The relative amounts of the two nickel porphyrin series $(\mathrm{DPEP} / \mathrm{etio}=2.0)$ support the idea that these sediments have not undergone substantial thermal treatment as suggested above by the abundance of chlorins at this depth.
The relatively low pigment yields, in comparison with the results obtained in the previous studies of Lower Cretaceous samples where the organic carbon content was roughly 0.5 to 2 per cent, are also noteworthy. Only the two samples discussed above (from Cores 75 and 122) contained more than $0.1 \mu \mathrm{g} / \mathrm{g}$ of pigment. The organic carbon values were not high in either case $(0.3$ and $0.6 \%$ ). Perhaps the discrepancy between the amount of organic carbon and the concentrations of extractable pigments is related to inhomogenity of the sediments and also to the presence of detrital oxidized terrestrial organic material. This may account for the samples having approximately 1 to 2 per cent organic carbon that contained only small amounts of extractable pigments. In turn, short-term high input of organic matter, perhaps even in the form of turbidity flows as indicated for the Barremian-lower Aptian strata (Leg 47 Shipboard Party, 1976), could account for the irregular trends in pigment concentrations observed. The presence of oxidized terrestial material may be coincident with the occurrence of odd molecular weight metalloporphyrins.

In contrast with the more detrital nature and oxidizing environment suggested for the Lower Cretaceous sediments from Hole 398D at over 1000 meters depth 
of burial, the Cretaceous sediments of the Cape and Angola basins (Leg 40) in the South Atlantic, also clastic in nature and now buried at 1000 to 1100 meters, were deposited in euxinic stagnant basins. This difference in depositional environments is seen to influence the resulting diagenetic products of chlorophyll that either are carried into the environment or formed in situ.

\section{ACKNOWLEDGMENTS}

This research was supported by the Oceanography Section of the National Science Foundation, Grants OCE 74-12438 A02 and OCE 77-07273. The authors thank Lynn Charney and Gerald DeMott for their help with sample work-up and Karl S. Schorno of Phillips Petroleum Company for his review of this manuscript.

\section{REFERENCES}

Baker, E. W. and Smith, G. D., 1975. Chlorophyll derivatives in DSDP Leg 14, 20, 26, 27 and 29 sediments. In Ingle, J. C., Karig, D. E., et al., Initial Reports of the Deep Sea Drilling Project, v. 31: Washington (U.S. Government Printing Office), p. 905-909.

Baker, E. W., Palmer, S., and Huang, W. Y., 1978a. Chlorin and porphyrin geochemistry of DSDP Leg 40
Sediments. In Bolli, H. M., Ryan, W. B. F., et al., Initial Reports of the Deep Sea Drilling Project, Supplement to Volumes 38, 39, 40 and 41: Washington (U.S. Government Printing Office), p. 639-648.

1978b. Intermediate and late diagenetic tetrapyrrole pigments, Leg 41: Cape Verde Rise and Basin. In Lancelot, Y., Seibold, E., et al., Initial Reports of the Deep Sea Drilling Project, v. 41: Washington (U.S. Government Printing Office), p. 825-838.

1978c. Early and intermediate chlorophyll diagenesis of Black Sea sediments: Sites 379, 380 and 381. In Ross, D., Neprochnov, Y., et al., Initial Reports of the Deep Sea Drilling Project, v. 42, Part 2: Washington (U.S. Government Printing Office), p. 707-716. 1978d. Miocene and Cretaceous tetrapyrrole pigments from Leg 44, Site 391. In Benson, W. E., Sheridan, R. E., et al., Initial Reports of the Deep Sea Drilling Project, v. 44: Washington (U.S. Government Printing Office), p. 639-644.

Palmer, S. E., Huang, W. Y., and Baker, E. W., 1979. Tetrapyrrole pigments from Bermuda Rise: DSDP Leg 43. In Tucholke, B., Vogt, P., et al., Initial Reports of the Deep Sea Drilling Project, v. 43: Washington (U.S. Government Printing Office), p. 657-662.

Shipboard Party - Leg 47, 1976. Passive continental margin, Geotimes, v. 21, p. 21-14. 